\title{
The tracks of thought
}

\author{
In both science and technology, metaphors direct \\ the way we think, reason and hypothesize.
}

0 genetic code, the rest came naturally. These four letters form the 'genetic alphabet'. Each group of three letters, or codon, represents a 'word', implying that there are 42424464 words in the 'genetic lexicon'. The process of copying DNA into RNA is referred to as 'transcription'; the step from RNA to protein synthesis is called 'translation'. Perhaps the most elegant metaphor is the palindrome, which refers to symmetrical DNA clones that read the same in both directions. In Who Wrote the Book of Life? (Stanford University Press, 2000), Lily Kay argues that modern genetic theory has been dominated by the metaphor of reading and writing and its associated connotations of codes and cryptography.

Genetics is not the only scientific field to have felt the lure of this metaphor. We also tend to describe the processes that occur in machines in terms of reading and writing. For a computer to process information, data must be 'machine-readable'. Storing new information in the place that was previously occupied by older information is called 'overwriting. Information, whether it comprises digits, music or graphs, can be 'written across' from working memory to the hard disk. Even the images stored in a hologram are 'read out' by laser beams. In both science and technology, the processes of reading and writing seem to have a firm grip on our nomenclature, if not on our imagination.

Language is both our most important vehicle of symbolic communication and the dominant medium in which information is externally stored. But if we wish to understand the seductive attraction of reading and writing as scientific metaphors, we should also be sensitive to the fact that

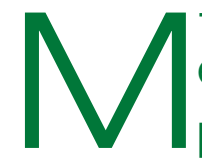

\section{etaphors,} particularly the powerful ones such as reading and writing, lay the tracks for our trains

\section{of associations.}

these are the very processes in which we conceptualize the most intimate of our own mental processes: remembering and forgetting. Virtually every medium for storing language has at one time been used as a metaphor for memory.

In his dialogue Theaetetus, Plato explains that memory is like a wax tablet, registering whatever we wish to remember. His pupils at the Academy probably carried wax tablets around, and it must have been a natural figure of speech to represent memory as a writing surface, the quality of which varied with the composition of the wax.

In the Middle Ages, as Mary Carruthers shows in The Book of Memory (Cambridge University Press, 1990), paper scrolls and books became the dominant metaphors for memory. After the death of Thomas Aquinas in 1274, his secretaries testified that his prodigious memory seemed to be incapable of forgetting anything, "as if knowledge were ever increasing in his soul, as page is added to page in the writing of a book".

In modern times, Freud compared human memory to a magic slate, with a surface layer that is periodically erased and therefore has unlimited capacity, and a deeper layer of wax which retains permanent traces of our experience. From the 1970s onwards, the most prominent model of memory has been the computer. When Alan Turing called the capacity of a computer to store information its "memory", he added that the machine had to "read" data from a tape.

Plato, Aquinas, Freud, Turing and present-day researchers obviously have widely diverging interpretations of memory. But what they all have in common is that they conceptualized the hidden processes of remembering and forgetting in terms of a metaphor that invokes a series of concrete, comprehensible images. This is precisely what metaphors are designed to do - they are not simply passive instruments of thought. Metaphors, particularly the powerful ones such as reading and writing, lay the tracks for our trains of associations. Whether we are investigating the mechanisms of memory or genetics, metaphors direct the way we think, name and hypothesize. Once

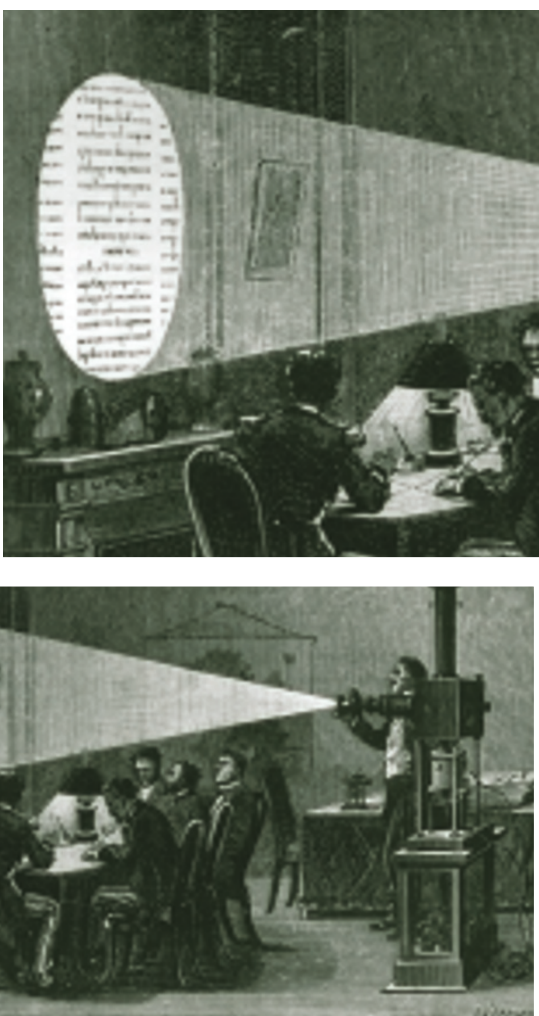

Microphotography found an early application in the military. During the German siege of Paris in 1871 , messages were photographed on extremely thin sheets of collodion and sent off using carrier pigeons. The procedure required a specially equipped reading room for the enlargement and transcription of dispatches. Illustration from De Natuur (1889), at the time the Dutch equivalent of Nature.

we start thinking along the lines of reading and writing, we will end up with memory traces as 'engrams' and cells containing 'genomic libraries'.

Is this a cause for concern? Perhaps one should not worry about the inevitable. In 1666, when Samuel Parker, a member of the Royal Society of London, advocated a general ban on the use of figurative language in scientific discourse, he expressed a particular horror at metaphors, whose "wanton and luxuriant fancies climbing up into the Bed of Reason, do not only defile it by unchast and illegitimate Embraces, but instead of real conceptions and notices of things impregnate the mind with nothing but Ayerie and Subventaneous Phantasmes".

But since then, neither geneticists nor psychologists seem to have heeded his warning. The fact of the matter is that we simply cannot escape metaphorical thinking. It comes as naturally to us as, indeed, it came to Parker.

Douwe Draaisma is in the Department of Theory and History of Psychology, State University of Groningen, Grote Kruisstraat 2/1,

9712 TS Groningen, The Netherlands. 